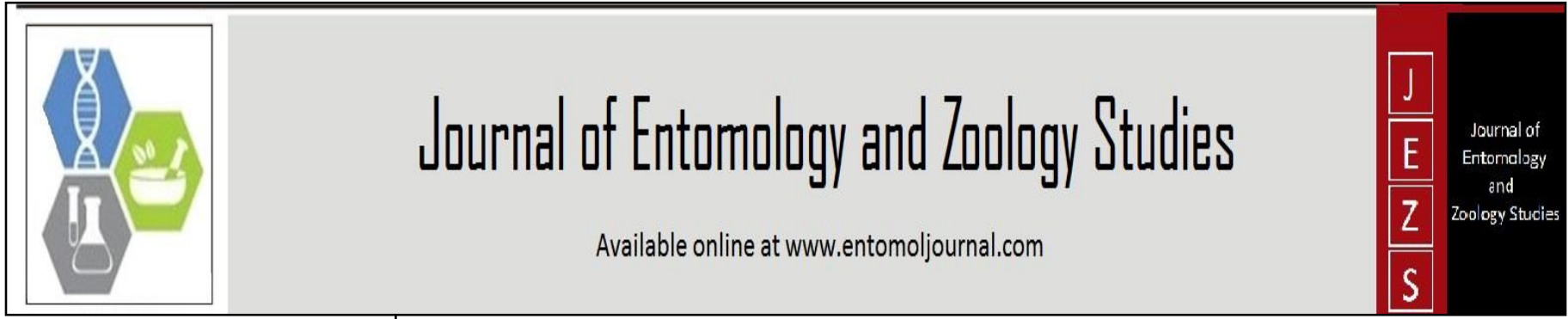

E-ISSN: 2320-7078

P-ISSN: 2349-6800

www.entomoljournal.com

JEZS 2021; 9(1): 778-780

(C) $2021 \mathrm{JEZS}$

Received: 19-11-2020

Accepted: 21-12-2020

\section{K Pratheepa}

Veterinary Assistant Surgeon,

Veterinary Dispensary,

Sambavarvadakarai, Tenkasi

District, Tamil Nadu, India

\section{AK Karuppiah}

Veterinary Assistant Surgeon,

Veterinary Dispensary,

Chinthamani, Tenkasi District,

Tamil Nadu, India

\section{K Vijay}

Veterinary Assistant Surgeon,

Veterinary Dispensary,

Poolangulam, Tenkasi District, Tamil Nadu, India
Corresponding Author:

K Pratheepa

Veterinary Assistant Surgeon,

Veterinary Dispensary,

Sambavarvadakarai, Tenkasi

District, Tamil Nadu, India

\section{Tail amputation - management of tumour like growth in tail of the cross-bred cows}

\author{
K Pratheepa, AK Karuppiah and K Vijay
}

DOI: https://doi.org/10.22271/j.ento.2021.v9.i1k.8239

\section{Abstract}

Diseases of the tail are common in cattle. They are prone to various affections like dermatitis, trauma, fracture, paralysis, luxation, necrosis, gangrene, diskospondylitis, tumours and tail rot. Tail affections may be treated conservatively or by amputation cranial to the affected area. Two cross-bred cows were referred and presented to the veterinary dispensary with the history of tumour like growth in the tail affecting the locomotion of the tail. Tumours were ulcerated and infested with maggots. Amputation of tail was done cranial to the affected part and given broad-spectrum antibiotics and NSAIDs for 5 and 3 days respectively. Both the animals recovered uneventfully.

Keywords: Management, tail amputation, tail affections, tumour

\section{Introduction}

Farm animals like cows use their tail as means of communication, locomotion and as an aid in their comfort, mainly to avoid the flies from biting the animal in response to skin irritation (Salib and Farghali, 2016) ${ }^{[4]}$. Just like its importance, the tail is prone to various affections like dermatitis, trauma, fracture, paralysis, luxation, necrosis, gangrene, diskospondylitis, etc. (Nuss and Fiest, 2011) ${ }^{[2]}$ and tumours of tail and tail rot can occur occasionally. Depending on the type of affection the management may vary. If unresponsive to medical treatment, the affections of the tail demand amputation. Two cross-bred cows with tumour in tail complicated with myiasis were presented in this report.

\section{Case History and Clinical observation}

A 5.5-year old crossbred jersey cow with foul-smelling tumour like growth complicated with myiasis in the tail tip (Fig-1) treated locally and a 5-year-old crossbred jersey cow with hard and round growth of $7 \mathrm{~cm}$ diameter infested with maggots on the ventral part of the base of the tail (Fig-2) were referred to the Veterinary dispensary. Both the animal had difficulty in lifting the tail and tumour growths were infested with maggots.

\section{Surgical Management and outcome}

Both the cases were complicated due to immobility of the tail, the risk of contracting flies, chronic nature and poor response to the treatment. Amputation of tail was carried out in both the animals after the consent from the animal owners.

The animals were sedated with the Xylazine Hydrochloride followed by epidural block using 2\% lignocaine Hydrochloride. Sedation with Xylazine Hydrochloride made the animal calm and facilitated easy restraint for standing positions. It also helped in handling the animal for injection of the local anaesthetic for epidural analgesia which is found to be suitable for desensitization of tail and subsequent amputation procedures. Amputation of the tail was carried by performing an epidural block by locating the sacrococcygeal space with the tip of a finger while flexing and extending the tail with the other hand. The $18 \mathrm{G}$ hypodermic needle was introduced at an angle of $45^{\circ}$ to the depth of about $1 / 2$ to 1 inch to enter the vertebral canal (Fig-1). $2.5 \mathrm{~mL}$ of $2 \%$ lignocaine Hydrochloride at a time was administered slowly to achieve caudal desensitization of tail.

The Surgical technique of tail amputation is as previously described by Tobias and Karen (2010) ${ }^{[6]}$ and in detail as described below. After application of tourniquet at the base of the tail, a 'U' shaped skin incision ( 1 to $2 \mathrm{~cm}$ ) distal to the joint space at the proposed amputation 
site was made on the dorsal and ventral surfaces of the tail given sufficient exposure to raise two triangular flaps of skin, the bases of which corresponded to the intervertebral space through which the disarticulation is to be effected. The attachments between the skin and vertebrae were transected using a scalpel blade. The skin and subcutaneous tissues cranial to the intervertebral space were elevated. The blood vessels lateral and ventral to the vertebral body cranial to the amputation site were ligated using absorbable suture (3-0). The tail was amputated cranial enough to the skin incision to provide a tension-free closure. With thumbnail and fingers, the bone was palpated to find its thickest portion. A scalpel blade was inserted perpendicular to the long axis of the tail into the ventral or dorsal joint space and the connecting ligaments and muscle was cut. The vertebra mid-body was transected and the remaining soft tissue attachments were cut. Haemorrhage during the operation was controlled effectively by applying tourniquet which was released subsequently and the bleeding points if any ligatured or torsioned with forceps. The skin was pulled over the bone end to evaluate flap length and the excessive ventral flap was trimmed so that the dorsal flap can be pulled over the bone tip. Proper skin apposition was achieved with simple interrupted sutures using No: 2 braided silk. After dressing with povidone-iodine the bandage was applied to protect the tail end. Post-operative management included administration of inj. Ceftriaxone with Tazobactum (Intacef Tazo, Intas Pharmaceuticals Ltd, $3375 \mathrm{mg}$, Intravenous) for five days and inj. Meloxicam $(0.5 \mathrm{mg} / \mathrm{kg}$, Intramuscular) for three days. Both the animals showed uneventful recovery.
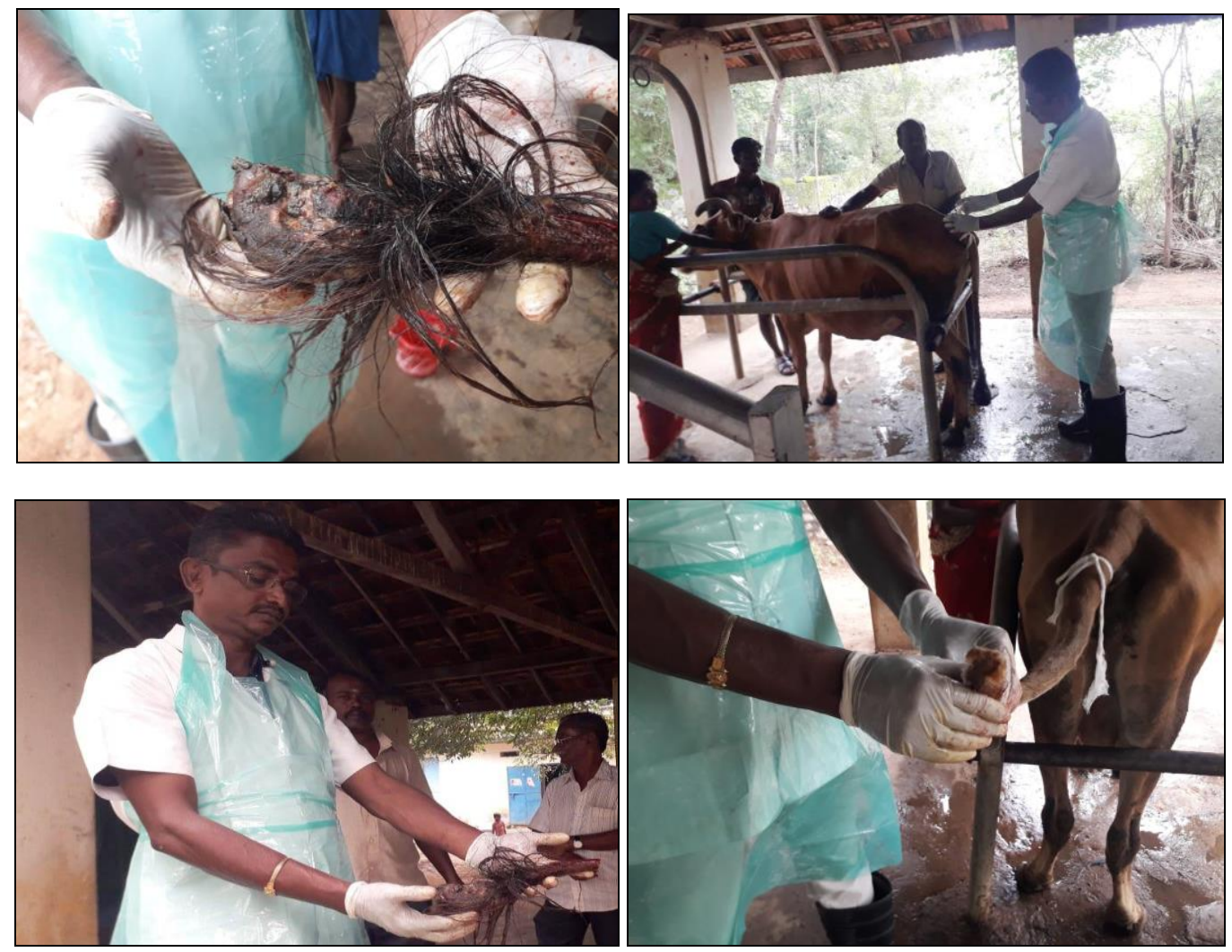

Fig 1: Case 1 - Surgical management of cross-bred cow with tumour like growth at the tip of the tail
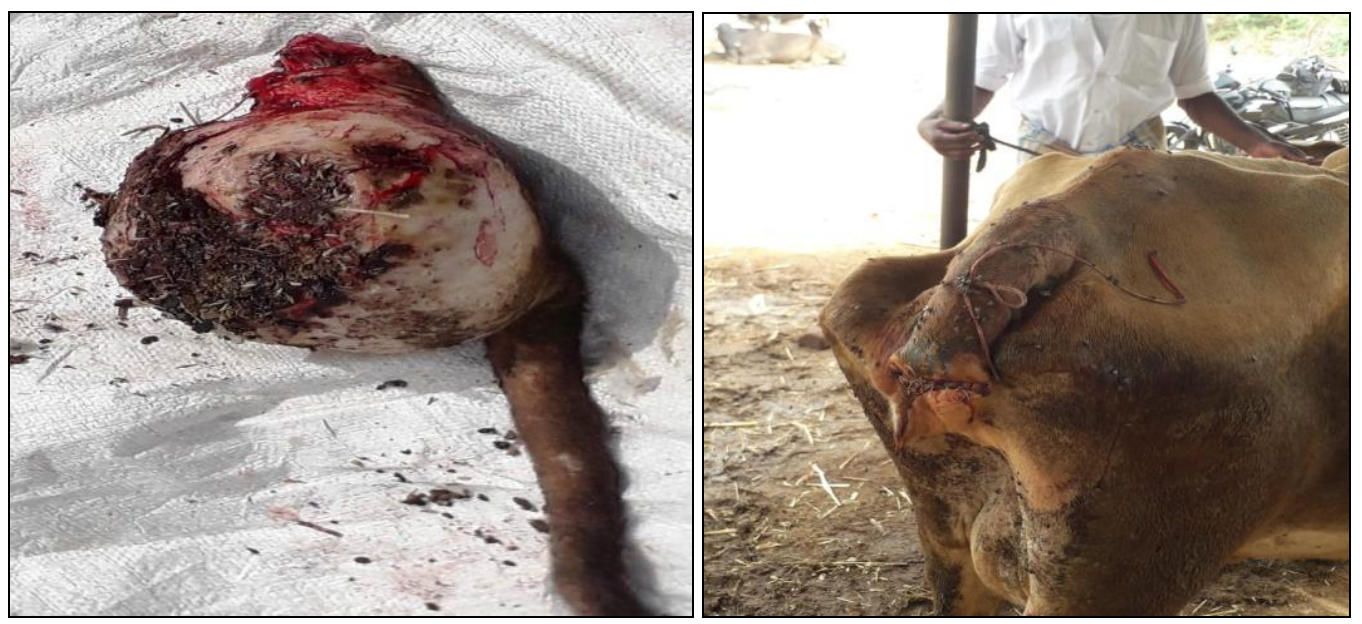

Fig 2: Case 2 - Surgical management of cross-bred cow with tumour like growth at the ventral part of the base of the tail 


\section{Discussion}

Diseases of the tail may be treated conservatively or by amputation cranial to the affected area. Tail amputation in cattle was a very controversial subject because in some countries, it was carried out prophylactically for management reasons without any medical indication. Most of these affections do not respond to routine medical management and demand amputation of the tail. Kerem Ural et al., (2007) [1] treated by amputation and administration of antibiotics and topical antibacterial applications. Olatunji-Akioye et al., (2010) ${ }^{[3]}$ and Nuss and Feist (2011) ${ }^{[2]}$ suggested amputation cranial to the affected area. Suresh Kumar et al., (2012) ${ }^{[5]}$ and Salib and Farghali (2016) ${ }^{[4]}$, reported tumours in tails and treated successfully with surgical excision.

\section{Summary}

In the present report, two cross-bred cows presented with tumour in the tail were treated by amputation of the tail and both the animals showed uneventful recovery.

\section{Acknowledgement}

We sincerely acknowledge the support provided by the Department of Animal Husbandry for conducting surgery and treatment.

\section{References}

1. Kerem Ural, Alic D, Karakurum MC, Aktas MS, Hydardedeoglu AE, Cingri CC. Tail tip necrosis in beef and dairy cattle: A report of seven cases in Ankara Kafkas. Univ. Vet. Fak. Derg 2007;13(2):203-207.

2. Nuss LK, Fiest M. Tail amputation for treatment of osteomyelitis of the first and second coccygeal vertebrae in a cow. Tierarzal Prax 2011;3(4):176-178.

3. Olatuunjii-Akioye, Omobowale, Olaifa, Abiola. Tail docking in an african lion (Panthera Leo). Israel Journal of Veterinary Medicine 2010;65(2):75-76.

4. Salib FA, Farghali HA. Epidemiological, therapeutic and surgical studies on Tail necrosis in Egypt. Inter J Vet Sci, 2016;5(2):58-63.

5. Suresh Kumar RV, Veena P, Sankar P, Dhanalakshmi N, Srilatha Ch, Kokila S. Trichoepithelioma in a buffalo: A case report. Buffalo Bulletin 2012;31(1): 4-5.

6. Tobias A, Karen M. Manual of small animal soft tissue surgery. Edition first, Wiley-Blackwell (C) 2121 State Avenue, Ames, Iowa 50014-8300, USA. 2010, 353-357. 